\title{
Analysis of Spatial Scenarios Aiding Decision Making for Regional Irrigation Water-Demand Planning
}

\author{
Tzai-Hung Wen ${ }^{1}$; Chun-Hung Lin²; Ching-Tien Chen ${ }^{3}$; and Ming-Daw Su ${ }^{4}$
}

\begin{abstract}
Regional irrigation water-demand planning is utilized to establish appropriate cropping patterns and estimate irrigation water demand. Although optimization methods have been extensively adopted, uncertainties of meteorological conditions and the complexity of spatial contexts make developing explicit and structured decision making extremely difficult. Rather than generating a single optimal solution, decision makers prefer to generate several possible scenarios and compare results. This study proposes a novel spatial scenariobased planning framework, with a database, model base, and scenario-setting modules, to generate flexible spatial planning scenarios for improving irrigation water-demand planning. Possible demand planning scenarios for irrigation managers are discussed. A prototype of the proposed scenario-based framework is implemented on a geographic information system platform to assist in spatial decision making. Demand planning during a drought period for the Chia-Nan irrigation command area, the largest one in Taiwan, is adopted as a case study to demonstrate the proposed framework for spatial scenario analysis.
\end{abstract}

DOI: 10.1061/(ASCE)0733-9437(2007)133:5(455)

CE Database subject headings: Decision support systems; Geographic information systems; Irrigation; Water management; Taiwan; Water demand.

\section{Introduction}

The purpose of regional irrigation water-demand planning is to set up suitable cropping patterns and estimate irrigation water demand for agricultural development. As irrigation consumes more than $60 \%$ of the total water supplies in Taiwan, irrigation water is considered as the major proportion of regional water demand in national water resource master plans and frequently as a potential water reallocation source for municipal or industrial sectors during drought. Thus, the relationship between irrigation water demands and cropping patterns is crucial to large-scale irrigation planning and for regional water resource allocation during severe droughts.

Decision making during regional irrigation water-demand planning typically involves many stakeholders and numerous competing objectives, such as maximum profits for farmers, maximum production for the agricultural sector, and minimum water consumption. Weighting these objectives is difficult for de-

\footnotetext{
${ }^{1}$ Postdoctoral Fellow, Center for Geographic Information Science, Academia Sinica, No. 128, Sec. 2, Academia Rd., Taipei, Taiwan 115.

${ }^{2}$ Ph.D. Candidate, Dept. of Bioenvironmental Systems Engineering, National Taiwan Univ., No.1, Sec. 4, Rd. Roosevelt, Taipei City, Taiwan 106.

${ }^{3}$ Associate Professor, Dept. of Civil and Water Resources Engineering, National Chiayi Univ., 300 Syuefu Rd., Chiayi City, Taiwan 600.

${ }^{4}$ Professor, Dept. of Bioenvironmental Systems Engineering, National Taiwan Univ., No.1, Sec. 4, Rd. Roosevelt, Taipei City, Taiwan 106 (corresponding author). E-mail: sumd@ntu.edu.tw

Note. Discussion open until March 1, 2008. Separate discussions must be submitted for individual papers. To extend the closing date by one month, a written request must be filed with the ASCE Managing Editor. The manuscript for this paper was submitted for review and possible publication on May 8, 2006; approved on December 4, 2007. This paper is part of the Journal of Irrigation and Drainage Engineering, Vol. 133, No. 5, October 1, 2007. CASCE, ISSN 0733-9437/2007/5-455-467/ $\$ 25.00$.
}

cision makers and, in some cases, these objectives are in conflict. Additionally, determining cropping patterns, which is the basis of irrigation water-demand planning, depends on numerous environmental and human factors. Environmental factors, such as climate, fertilizer use and crop yields, are mostly spatially distributed. Certain human factors are tangible, such as irrigation methods and systems efficiency, whereas others, such as farmer experiences and farming know how, are not (Sattarasart et al. 2002). Developing an explicit and structured decision making process is difficult due to the multiple implicit objectives and factors affecting cropping patterns. Therefore, in practice, decision making typically depends on the experience of water managers rather than mathematical decision models.

Despite the nonstructured nature of the decision-making process, researchers commonly employ structured approaches such as system optimization to determine optimal cropping patterns for regional irrigation planning. Linear programming models have been extensively applied to establish optimal cropping patterns that maximize net return or crop yield (Raman et al. 1992; Prajamwong et al. 1997; Singh et al. 2001). To improve the efficiency in identifying optimal solutions, heuristic algorithms, such as genetic algorithms, have been employed to solve optimal cropping pattern problems (Lilburne et al. 1998; Kuo et al. 2000). Complex mathematical programming models, such as nonlinear, stochastic, or dynamic programming, also have been applied to identify optimal cropping patterns (Kumar et al. 1998; Sabu and Sudhindra 2000; Kipkorir et al. 2002). However, these optimization techniques only work in specific predefined situations. Once significant changes occur (e.g., changes in land use, climate, or irrigation practices), decision makers cannot rely on these predefined "optimal" cropping patterns, but rather need tools to reformulate the problems, establish the models, and validate analytical results. As a result of these inflexible or inefficient processes, decision makers require additional alternatives for 
evaluation, including tools for scenario building and making comparisons among scenarios (Buras 2000).

Therefore, rather than determining optimal cropping patterns, this study proposes a novel nonstructured planning framework that allows decision makers to generate and compare planning scenarios. For instance, scenario-based planning makes it possible to evaluate the effects on water-demand reduction when the irrigated area is reduced or if some paddy fields are shifted to other crops that require reduced amounts of water. Increased flexibility for evaluating alternatives improves the effectiveness of decision making in regional irrigation demand planning. The proposed framework is for developing a scenario-based planning process using a geographic information system (GIS) platform to aid water managers in spatial decision making during irrigation demand planning. Demand planning during a drought in the ChiaNan irrigation command area, the largest one in Taiwan, is used as a case study demonstrating the proposed framework for spatial scenario analysis.

\section{Concepts of Scenario-Based Planning}

The concept of scenario planning is not new to systems evaluation. From business strategic planning to environmental analysis, the use of scenario planning is common in the planning community (Klein 1994; Deaton and Winebrake 1999; Martin et al. 2003). For example, in municipal water-demand forecasting, different scenarios are commonly developed based on population growth, economic development, or pricing policies that have certain probabilities of occurring in the future (Levite et al. 2003). Water-supply plans are then evaluated under these scenarios. However, decision makers can only evaluate a single alternative or a small number of estimates, whereas the future can include a combination of different scenarios (Zegras et al. 2004).

A scenario in this study is a proposed combination of policies and probabilistic events. Scenarios induced by decision makers are often called decision scenarios, and those occurring by chance are considered as probabilistic scenarios (Wack 1985). Scenariobased analysis is a planning tool that assists decision makers in generating possible preferred scenarios in complex decision processes (Stewart and Scott 1995). This approach differs from conventional planning approaches, such as prediction or optimization. Rather than providing a single optimal solution, scenariobased analysis allows decision makers to establish scenarios based on specific criteria to determine the complexity of systems, generate experience and knowledge from different combinations of possible future events, and finally, produce effective and robust strategies or decisions.

\section{Scenarios for Irrigation Water-Demand Planning}

Due to rapid population growth and socioeconomic development, water-shortage problems have increased. Agricultural, municipal, and industrial sectors have been impacted by droughts with increasing frequency in the last decade. Because of poor economic efficiency in addition to political and national economic concerns, irrigation water is considered a temporary water source that can be reallocated to meet municipal and industrial needs during severe droughts. Although optimization techniques are intensively used for optimal cropping patterns, the purpose of irrigation water-demand planning is not confined to maximizing crop yields or for farming benefit (Raman et al. 1992; Kipkorir et al. 2002).
One challenge irrigation managers in Taiwan face is how to establish appropriate cropping patterns that use decreased amounts of water during severe droughts in the short term and meet national food supply needs in the long term. Optimal cropping patterns can be solved using predefined conditions; however, it may not be an optimal solution for decision makers during actual irrigation planning practice. Irrigation managers need to understand the complexity of irrigation demand planning and accumulate the knowledge and experience necessary for evaluating the impacts of cropping pattern change on irrigation water demand. The proposed scenario-based planning model provides irrigation managers with a wide range of information to establish suitable — which may not be optimal—cropping patterns under possible planning scenarios.

Irrigation water-demand planning requires that cropping patterns be established through investigating crops, soils, and meteorological conditions. When water supply does not meet the planned irrigation demand, management measures and planning strategies must be developed and evaluated (Fig. 1). Possible planning settings, also called planning scenarios, include changing cropping patterns and improving irrigation management practices. This study discusses both probabilistic and decision scenarios.

\section{Probabilistic Scenarios}

Crop-water requirements are affected primarily by meteorological conditions, such as temperature, precipitation, sunshine hours, and wind velocity. Irrigation managers have to evaluate possible variations in irrigation water demand due to meteorological changes. Therefore, three meteorological conditions-meteorologically optimistic, pessimistic, and most likely-are incorporated into scenario-based planning in this study. First, the meteorologically optimistic condition has a relatively low temperature and high precipitation. Under this scenario, the cropwater requirement is the lowest for demand estimations. Second, the pessimistic scenario has a relatively high temperature and low amount of precipitation. As high temperature generates high evapotranspiration and low precipitation provides minimal rainfall for fields, additional irrigation water is needed. Irrigation managers can compare the differences between these two extreme conditions to acquire knowledge for identifying the impact of climatic uncertainty on water demand. Third, the most likely scenario has average precipitation and temperature.

\section{Decision Scenarios}

When the water supply cannot meet planned irrigation water demand, cropping patterns must be rearranged. The following considerations must be addressed when making decisions about cropping patterns.

\section{Planting Date}

Although adjusting the planting date has little impact on total seasonal irrigation water demand, irrigation managers should establish staggered planting dates that mitigate the demand peak to increase management efficiency and flexibility.

\section{Planting Crops}

Rice is a major cash crop in Asian countries such as Taiwan, and it can be harvested twice each year in some regions. Reducing the area planted with such water-intensive crops can reduce irrigation 


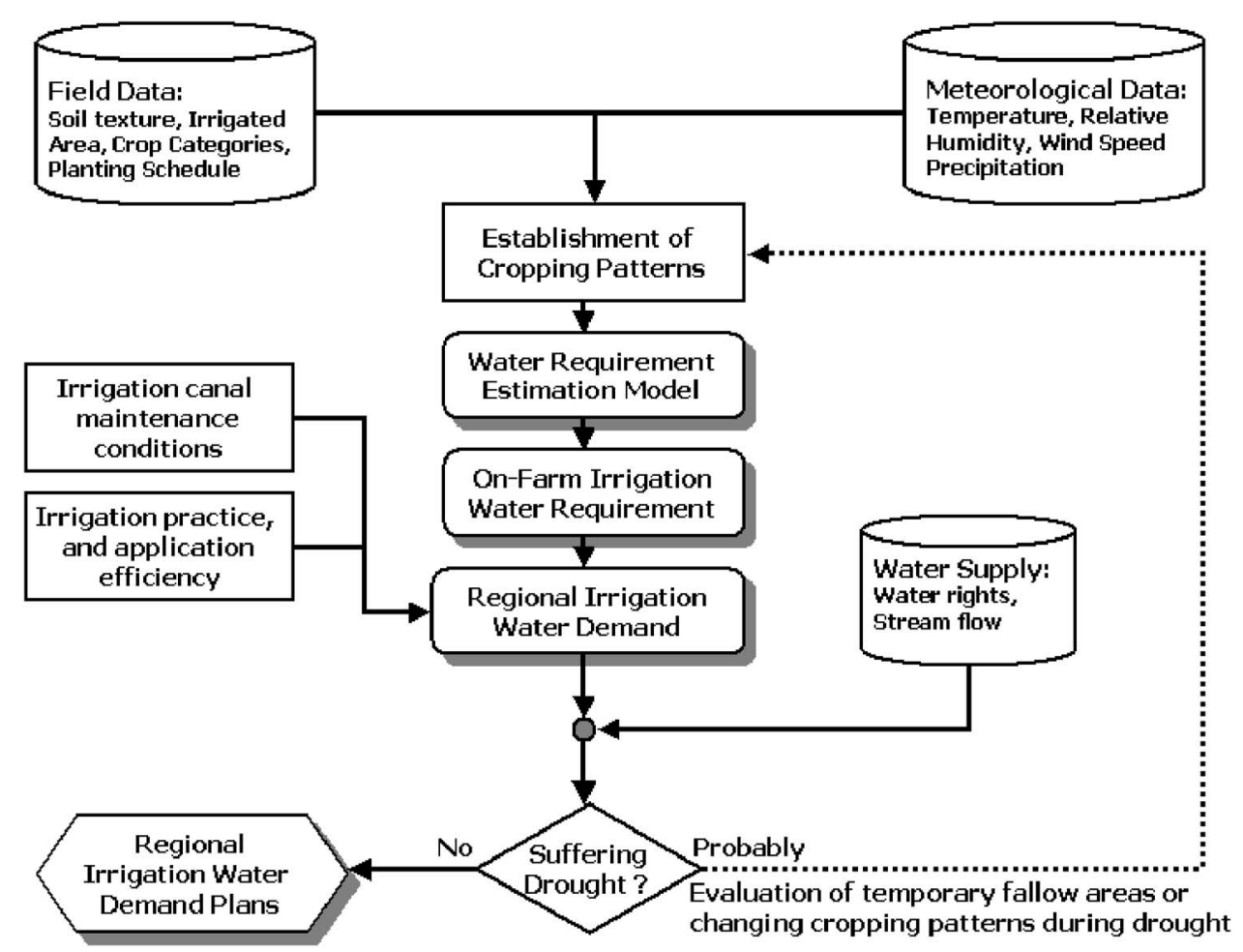

Fig. 1. Planning process for regional irrigation water demand

water demand. Irrigation managers should evaluate the impact that reducing irrigated rice paddies or switching to other crops has on irrigation water demand.

\section{Fallow Regions}

In addition to crop categories, the decision to leave some irrigated areas fallow is also a critical issue during irrigation demand planning, especially for drought years. The process of decreasing regional irrigation demand by leaving land fallow requires identification of areas that are to be left fallow. Spatial information such as that for original planted crops, soil percolation potential, canal lining and maintenance, and distance to water sources must be considered during this decision process. Decision makers may have to try leaving different combinations of areas fallow before achieving satisfactory results.

\section{Irrigation Practice and Management}

Improvements in irrigation practices and management, such as lining canals to reduce conveyance loss and improving the efficiency of applying water to fields, can also reduce water consumption. Notably, most of these measures cannot be accomplished in the short term and are usually considered as long-term scenarios.

Scenario-based planning is complex and unstructured and is likely composed of probabilistic and decision scenarios. Table 1 lists probabilistic and decision scenarios for irrigation waterdemand planning. The scenario-based planning framework proposed in this study provides water managers with tools for developing and analyzing scenarios. Spatial scenarios, which can be established easily using a map-based graphical user interface (GUI), can be used to identify the impacts of decisions on waterdemand planning.

\section{Model Framework}

The proposed scenario-based planning framework has three modules: A database, model-base module, and a tool for establishing scenarios and presenting results. Most decision scenarios involve spatially distributed information, such as canal networks and cropping patterns, in addition to data for agricultural production. A GIS is integrated into the proposed framework to handle spatial data. In addition to efficient data management, the GIS provides decision makers with spatial orientation and visualization capabilities to flexibly produce and adjust decision scenarios and effectively compare irrigation water-demand distributions spatially

Table 1. Planning Scenarios of Regional Irrigation Water-Demand Planning

\begin{tabular}{|c|c|}
\hline Perspectives & Possible scenarios (measures) \\
\hline $\begin{array}{l}\text { Probabilistic } \\
\text { (meteorological } \\
\text { uncertainty) }\end{array}$ & $\begin{array}{ll}\text { 1. } & \text { Optimistic (low temperature/high rain) } \\
\text { 2. Pessimistic (high temperature/low rain) } \\
\text { 3. Most likely (average temperature and rain) } \\
\text { 1. Planning date } \\
\text { 2. Planting crops } \\
\text { - Paddy or other crops }\end{array}$ \\
\hline $\begin{array}{l}\text { Human induced } \\
\text { (in response to } \\
\text { water shortage) }\end{array}$ & $\begin{array}{l}\text { 3. Fallow regions (area and location) } \\
\text { - Canal systems } \\
\text { - Irrigation administrations } \\
\text { - Environmental characteristics } \\
\text { 4. Irrigation practice } \\
\text { - Canal lining } \\
\text { - Application efficiency }\end{array}$ \\
\hline
\end{tabular}




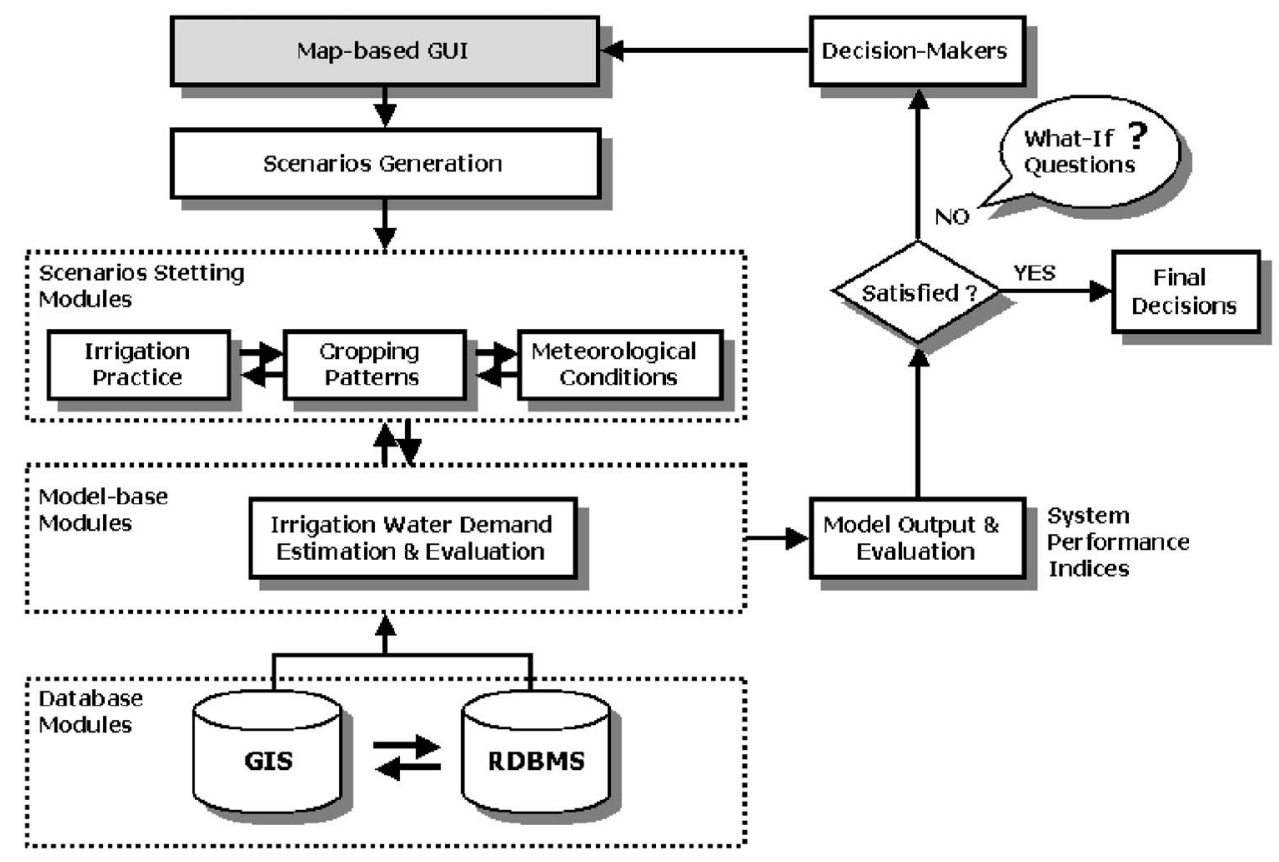

Fig. 2. A scenario-based simulation model framework

and temporally. Fig. 2 presents the framework for the simulation model and decision-making process.

\section{Database Module}

The database module is the basis for the simulation model. Data associated with irrigation demand estimation are collected and managed using the relational database management system (RDBMS). The GIS is utilized to manipulate spatially distributed data other than numerical and categorical data. Microsoft Access is used as the RDBMS and ESRI Arcview GIS is employed for spatial data management. Microsoft Visual Basic is utilized as a programming tool for integrating the RDBMS and GIS. Table 2 lists data items associated with irrigation water-demand planning.

\section{Climate}

Climate data, including temperature, rainfall, humidity, sunshine hours, and wind velocity, which are necessary for determining crop water requirements and estimating effective rainfall, are recorded in the climate database. This study uses a ten-day period as the temporal unit. The stochastic characteristics of temperature and precipitation are of concern in this study. Data recorded during 1970-2005 were analyzed and statistical exceedance probabilities of $95 \%, 50 \%$, and $5 \%$ were generated for planning purposes. Climate data with exceedance probabilities by $95 \%$ and $5 \%$ were used in this study to represent the two extreme meteo- rological scenarios; the scenario with a probability of $50 \%$ was considered the most likely scenario. These three settings can be used to examine the effects of climatic uncertainties on irrigation water demand.

\section{Soil}

Soil characteristics are important for estimating field irrigation application efficiency and percolation loss. Soil texture information was determined from topsoil at $30 \mathrm{~cm}$ increments to a depth of $150 \mathrm{~cm}$. However, the natural variation in soil characteristics typically does not follow man-made administration boundaries. The soil map was overlaid onto the irrigation administration unit map. The soil characteristics for each irrigation administration unit were generated by adopting the weighted average of the area of each soil type.

\section{Command Area}

The average farm size in Taiwan is approximately 0.7 ha. Farms are grouped into basic administration units, called irrigation groups, approximately 150 ha in size. In this study, the spatial database for irrigation groups is established with detailed attribute data, including name and administration hierarchies, irrigation areas, area of rice paddies, cropping patterns, water sources, and percolation. There are four major cropping patterns in the study region. The first two cropping patterns are one or two rice paddy

Table 2. Database for Regional Irrigation Water-Demand Planning

\begin{tabular}{lll}
\hline Database format & Categories & \\
\hline GIS database & Climate & Detailed items \\
(ESRI shape files) & Soil & Temperature, humidity, sunshine hours, wind velocity \\
& Canal network & Textures, percolation \\
& Command area & Canal length and topology, conveyance efficiency, irrigated area \\
Relational database & Crops & Cropping patterns, irrigation administration units \\
(Microsoft Access files) & Irrigation & Crop categories, crop coefficients $\left(K_{c}\right)$ \\
\hline
\end{tabular}




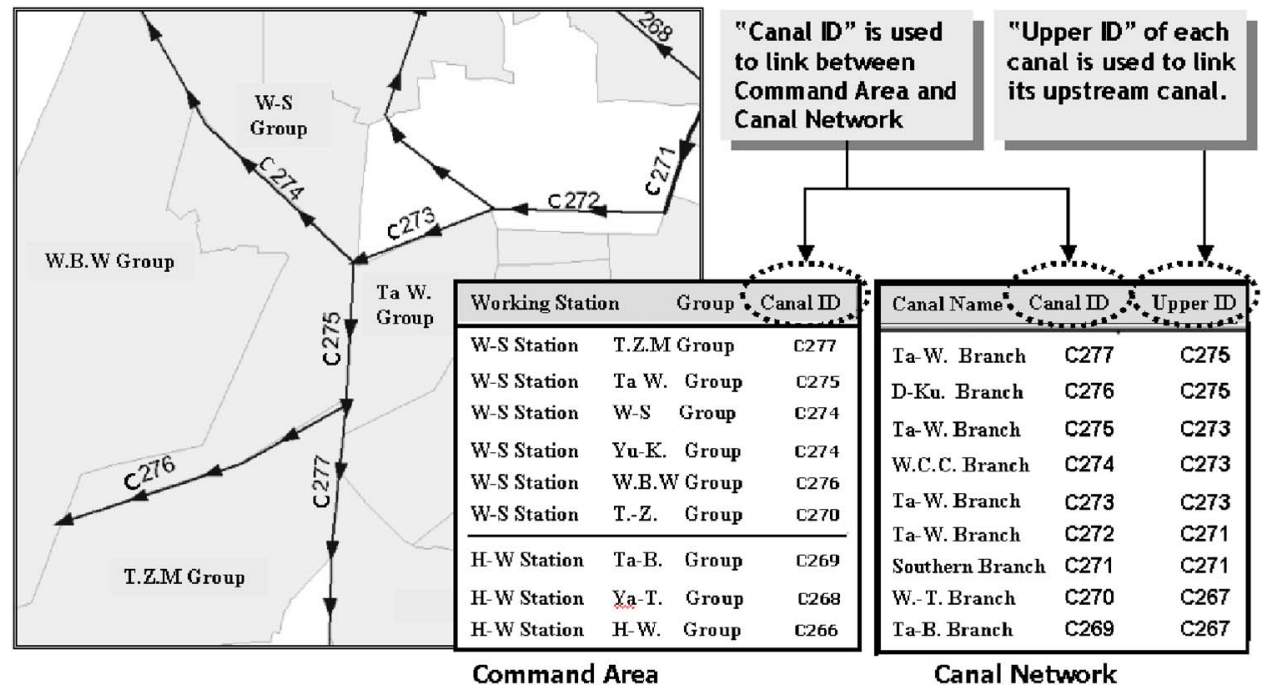

Fig. 3. Links between canal network and irrigated area

crops in each year. The other two cropping patterns are called "rotational cropping patterns." Each irrigation group is divided into three rotational units. One or two rotational units are planted in the rice paddies, and the remaining crops are corn, sorghum, soybean, or sugarcane, each of which uses less water than rice. The rice paddy units are rotated annually to maintain equity among farmers. In this model, different combinations of cropping patterns are set for each irrigation group and aided by map-based GUIs.

\section{Canal Network}

Canal network data are essential for irrigation-demand planning. To estimate regional irrigation water demand, conveyance loss must be added to on-farm irrigation requirements. Water conveyance loss is based on factors such as canal material, maintenance conditions, and management practices. In addition to estimating conveyance loss, the spatial relationships between canal systems and command areas are also crucial to irrigation-demand planning and water management. Decision makers can create spatialplanning scenarios based on canal network systems. Therefore, a structured coding system is proposed for network representation of canal systems (Fig. 3). Wen et al. (2004b) discussed in detail the spatial data structure of irrigation canal systems. With the proposed data structure, an operator can trace a network either upstream to water diversion or downstream to farms. The canal total length and canal types (lined or unlined) up to a water source can be traced. Furthermore, the irrigated area can be identified for each point in a network. This information is effective for planning cropping patterns and irrigation management.

\section{Crops and Irrigation Database}

The crop database consists of crop data related to irrigation planning, including crop coefficients $K c$, crop categories, and suitable planting dates. Because crop coefficients vary for different regions, a user-defined mode was constructed for the proposed model that allows users to alter default data and thereby increase model flexibility. In addition to the principal paddy crop, data for corn, soybean, sorghum, and sugar cane are incorporated into this crop database. Factors and parameters affecting irrigation water estimation, such as application efficiency and planting schedules, are also recorded in the irrigation database.

\section{Model-Based Module}

The model-based module is the engine that processes data in this scenario-based planning model for irrigation-demand calculation. The module is composed of related models for large-scale irrigation water-demand estimations. The estimation process involves several significant factors, including reference evapotranspiration $\left(E T_{0}\right)$, crop coefficients, effective rainfall, soil textures, canal conveyance, and application efficiency. The mathematical expression is

$$
W=\sum_{t=1}^{T} \sum_{s=1}^{m} \frac{\left(\sum_{i=1}^{n}\left(A_{i, s} \times K c_{i, t} \times E T o_{i, s, t}\right)\right)+P_{s, t}-A R_{s, t}}{0.01 \times E_{s, t}}+L_{s, t}
$$

where $A_{i, s}=$ irrigated area for crop $i$ in the $s$ th irrigation group $\left(\mathrm{m}^{2}\right) ; \mathrm{AR}_{s, t}=$ effective rainfall $(\mathrm{mm} /$ day $) ; \mathrm{E}_{s, t}=$ application efficiency $(\%) ; E T o_{i, s, t}=$ reference crop evapotranspiration of crop $i$ at time $t$ in the $s$ th irrigation group (mm/day); $K c_{i, t}=$ crop coefficient of crop $i$ at time $t ; L_{s, t}=$ canal conveyance loss $\left(\mathrm{m}^{3}\right), P_{s, t}=$ soil percolation rate $(\mathrm{mm} /$ day); and $W=$ annual regional irrigation water demand $\left(\mathrm{m}^{3}\right)$.

A procedure-based GUI (Fig. 4) allows water managers to supervise these factors. Water managers can also obtain an overview of the entire management decision process through this easy-ofuse user interface. Although the Penman-Monteith method is generally accepted as the standard model for estimating reference $E T$ $\left(E T_{0}\right)$ in the research community (George et al. 2002), the method needs relatively detailed local meteorological parameters, such as the psychrometric constant, solar radiation, and saturated vapor pressure curves. In some developing countries, these local parameters are seldom available to water managers and irrigation administrators. Additionally, most $E T_{0}$ estimation methods, including the modified Blaney-Criddle method (Blaney and Criddle 1950), Thornthwaite method (Thornthwaite 1948), and PenmanMonteith method (Monteith 1965) are empirical approaches. The performance of different methods varies with meteorological conditions and data availability. Therefore, generating agreement for an appropriate model is difficult (George et al. 2002). In this 


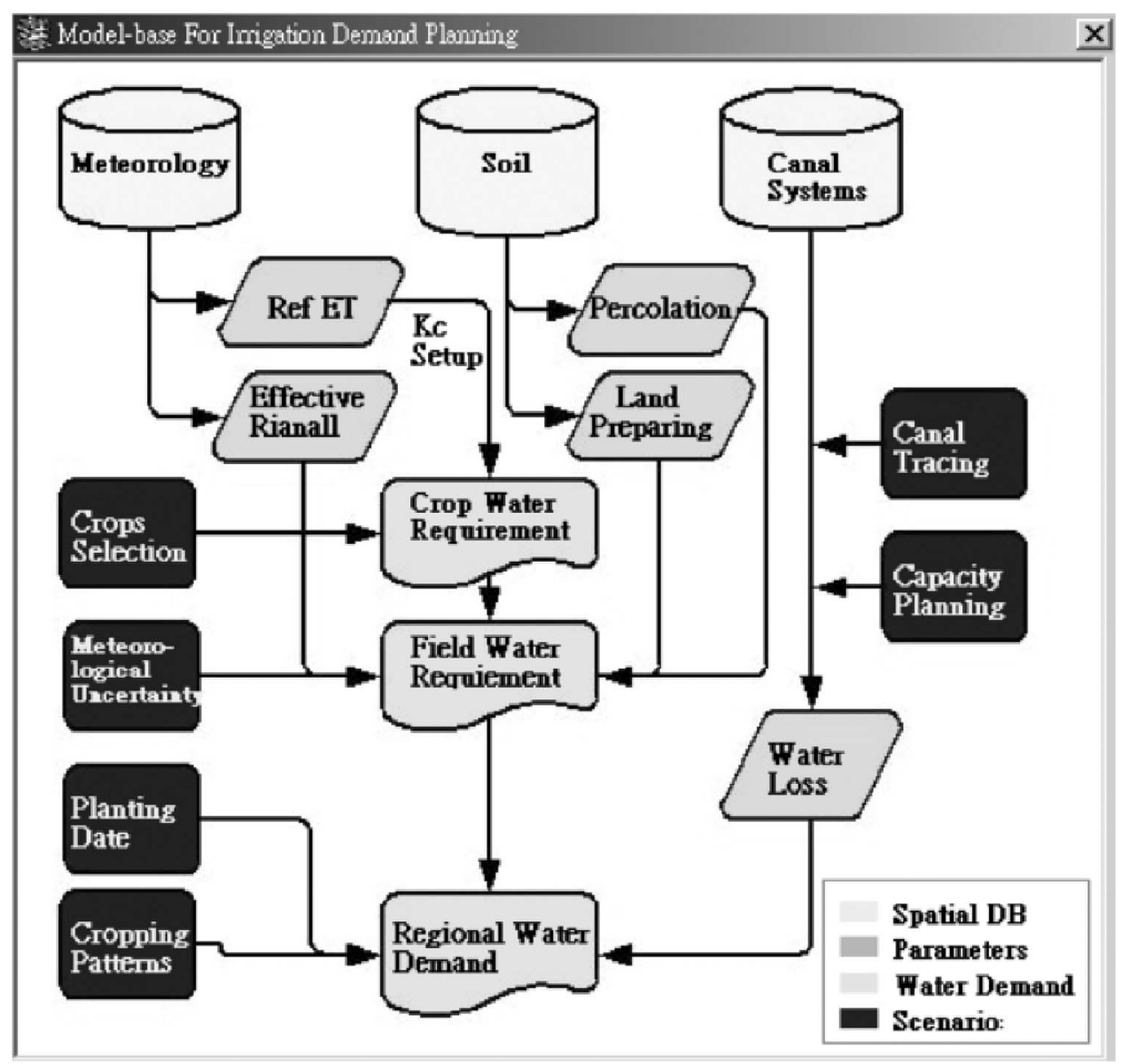

Fig. 4. Procedure-based GUI of model-base modules

study, the commonly used $E T_{0}$ estimation models, including the modified Blaney-Criddle and Penman-Monteith methods, are integrated into the system. An adaptive interface is also provided for additional estimation models.

Discrepancies in demand estimations using different models can result in controversies regarding competing demands for limited water in regional water reallocation. For instance, the radiation method used in arid conditions is unpredictable and typically underestimates evapotranspiration, whereas the modified Penman model generally overestimates $E T_{o}$ by up to $20 \%$, for conditions in which evaporation is low (Allen et al. 1998). Different water sectors choose the estimation model that is most beneficial to their needs. Therefore, the model-base module in this proposed scenario-based framework can provide water managers with a variety of models for choice in estimation of water demands. Variation in water demands caused by different models can prove beneficial when rationally dealing with water allocation issues among different sectors. Fig. 5 shows the interactions between the database and model-based modules. Wen et al. (2004a) provides a detailed description of the process of integrating the irrigation demand estimation model with GIS.

\section{Scenario Setting and Presentation Module}

Scenario setting and the tools for presenting analytic results form essential connections between the model and users. This module allows users to generate flexible decision scenarios they require, and displays the comparative information for these decisions.

\section{Map-Based Scenario Setting}

The proposed framework includes default settings with the current operating situations as the default scenario and a starting point for users. The water managers can set up different planning scenarios to simulate actual or hypothesized changes in operational environments of the water systems based on their domain knowledge and decision rules. Scenario setting involves a massive quantity of data changes for irrigation planning. For instance, changing cropping patterns for a region may require editing data for each irrigation group. This operation is tedious and can easily introduce errors into the editing process. The map-based interface (Fig. 6) is very efficient and effective for generating spatial scenarios. Users can identify a spatial region and modify the related information through an interactive dialogue box. The GIS in this study integrates spatial data and provides a platform for this mapbased operational environment. Decision makers can first select regions via spatial queries and generate planning scenarios accordingly. For instance, a decision maker can identify areas with high percolation potential using the GIS and designate these regions as fallow to decrease irrigation demand during droughts.

\section{Results Summary and Comparison}

The proposed scenario-based simulation model enables decision makers to obtain an overview of system behavior by comparing 


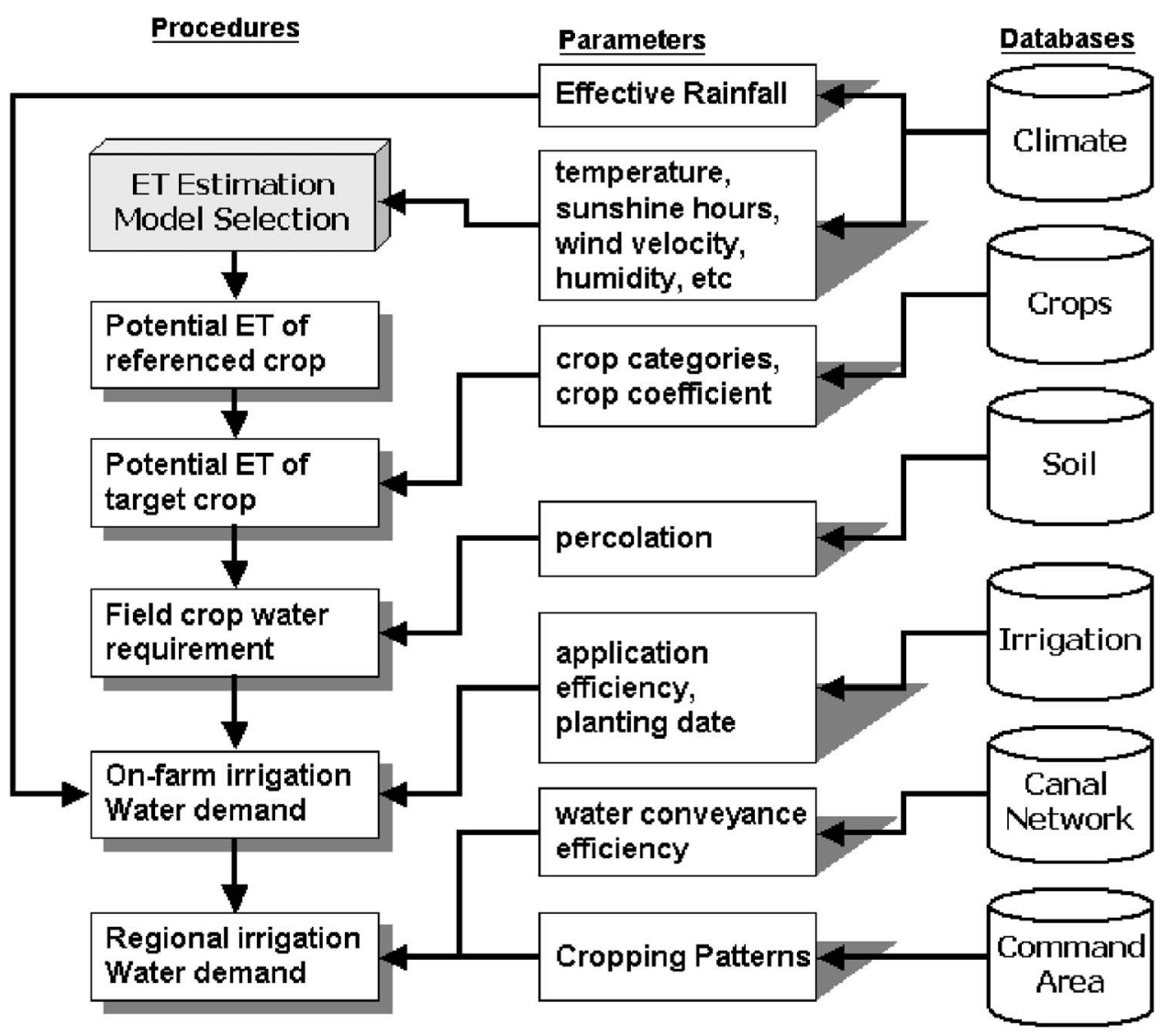

Fig. 5. Regional irrigation water-demand estimation framework

system performance resulting from different system settings. Managers (or decision makers) must have detailed information regarding system performance for different scenarios via tables and charts so they can compare the impact of decision alterna- tives. Some evaluation indices, including water demands, irrigated areas, and fallow impact effects were used for performance comparison among different scenarios. The impacts of fallow indices are based on two important characteristics: (1) The fallow

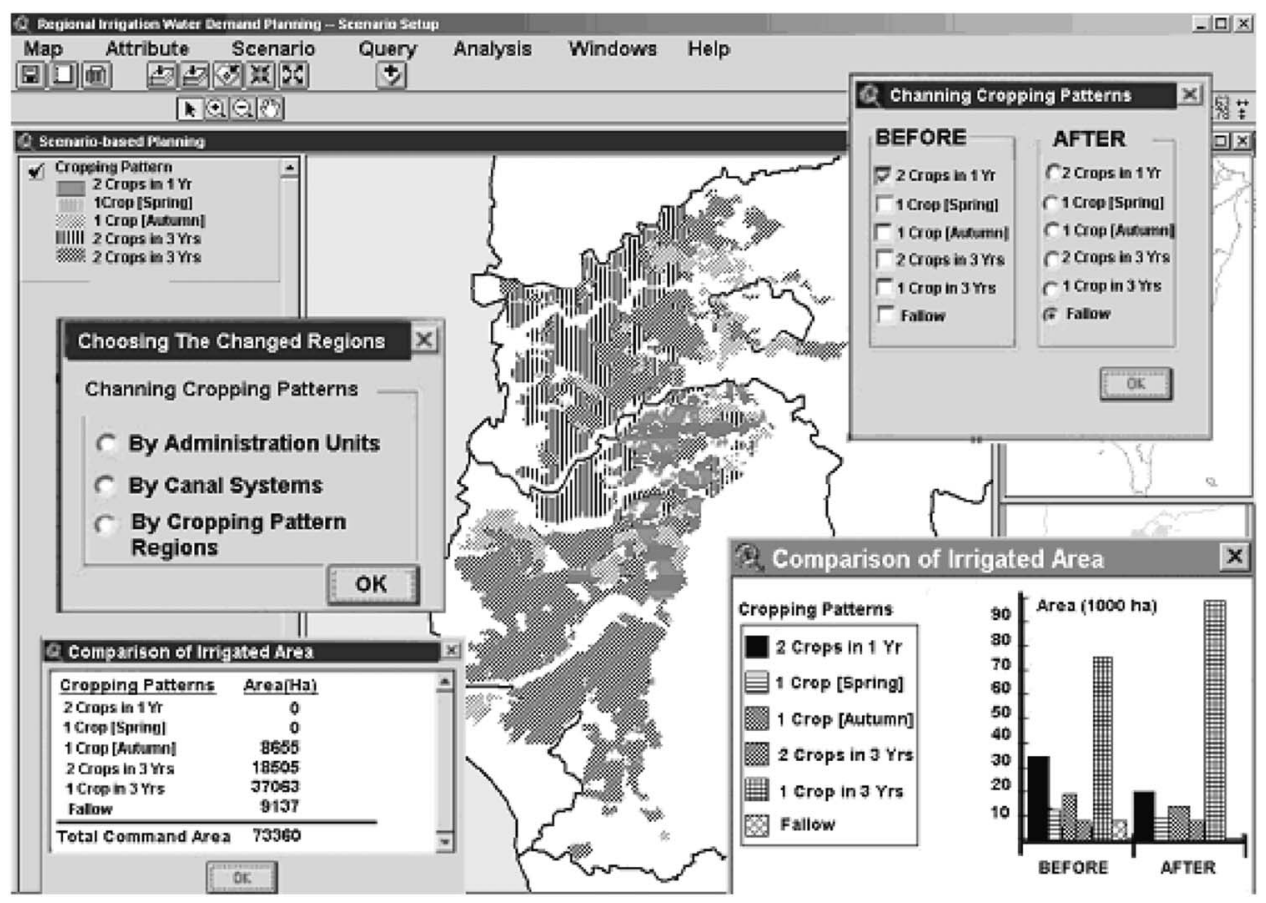

Fig. 6. Interface of the scenario generator 


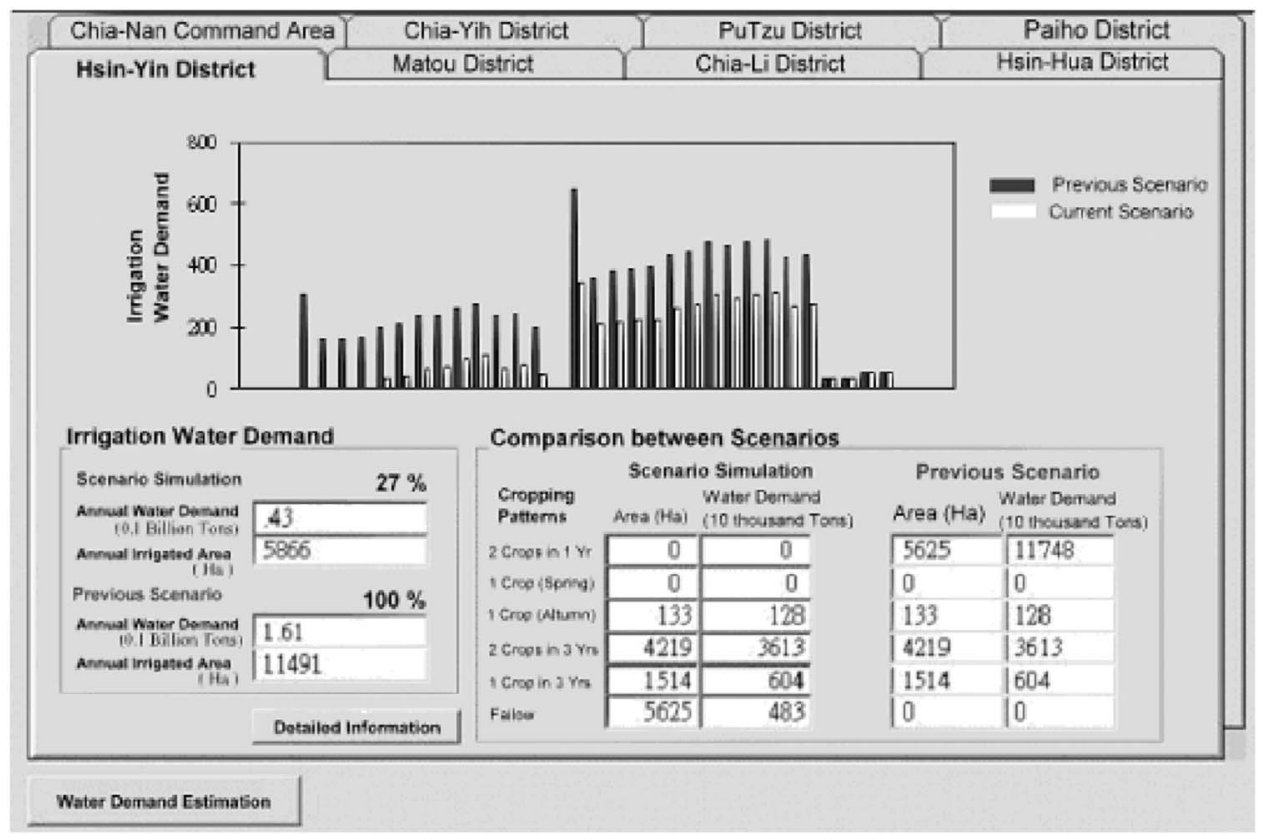

Fig. 7. Interface of the presentation tool

scale, determined by the ratio of fallow to total irrigated areas and the ratio of fallow to total paddy areas (Chang 2006); and (2) the fallow equity in a spatial dimension based on the spatial clustering tendency of fallow areas, which is expressed as (Wang 2006)

$$
G=\frac{\sum_{i} \sum_{j}\left(W_{i j} X_{i} X_{j}\right)}{\sum_{i} \sum_{j}\left(W_{i j}\right)}
$$

where $G=$ evaluation index for measuring the spatial clustering tendency of fallow areas; $\mathrm{W}_{i j}=$ binary matrix, which is equal to 1 when two areas are contiguous and 0 otherwise; $\mathrm{X}_{i}=$ binary state variable, which is 1 for the fallow state and 0 for the irrigation state in area $i$. The index range is $0-1$, and the size of the value is positively correlated with fallow area clustering, which can markedly affect fallow equity.

Furthermore, an irrigation association in Taiwan has several management districts. In addition to overall evaluation indices, decision information in each management district can be presented in each tab (Fig. 7). Decision makers can identify detailed information for each management district by choosing different tabs among different scenarios.

\section{Case Study: Application of Spatial Scenario Analysis}

The Chia-Nan Irrigation Association, covering the largest command area in Taiwan, was selected as a study area to demonstrate the feasibility of the proposed scenario-based planning framework. The primary water-supply source for this command area is from the Wu-San-To (WST) Reservoir, which allocates 900 $\times 10^{6} \mathrm{~m}^{3}$ of water annually to irrigation, accounting for approximately $95 \%$ of the regional total irrigation demand. The entire irrigation area, approximately 78,000 ha, is divided into seven management districts (Fig. 8). Each management district consists of several workstations, and each workstation is further divided

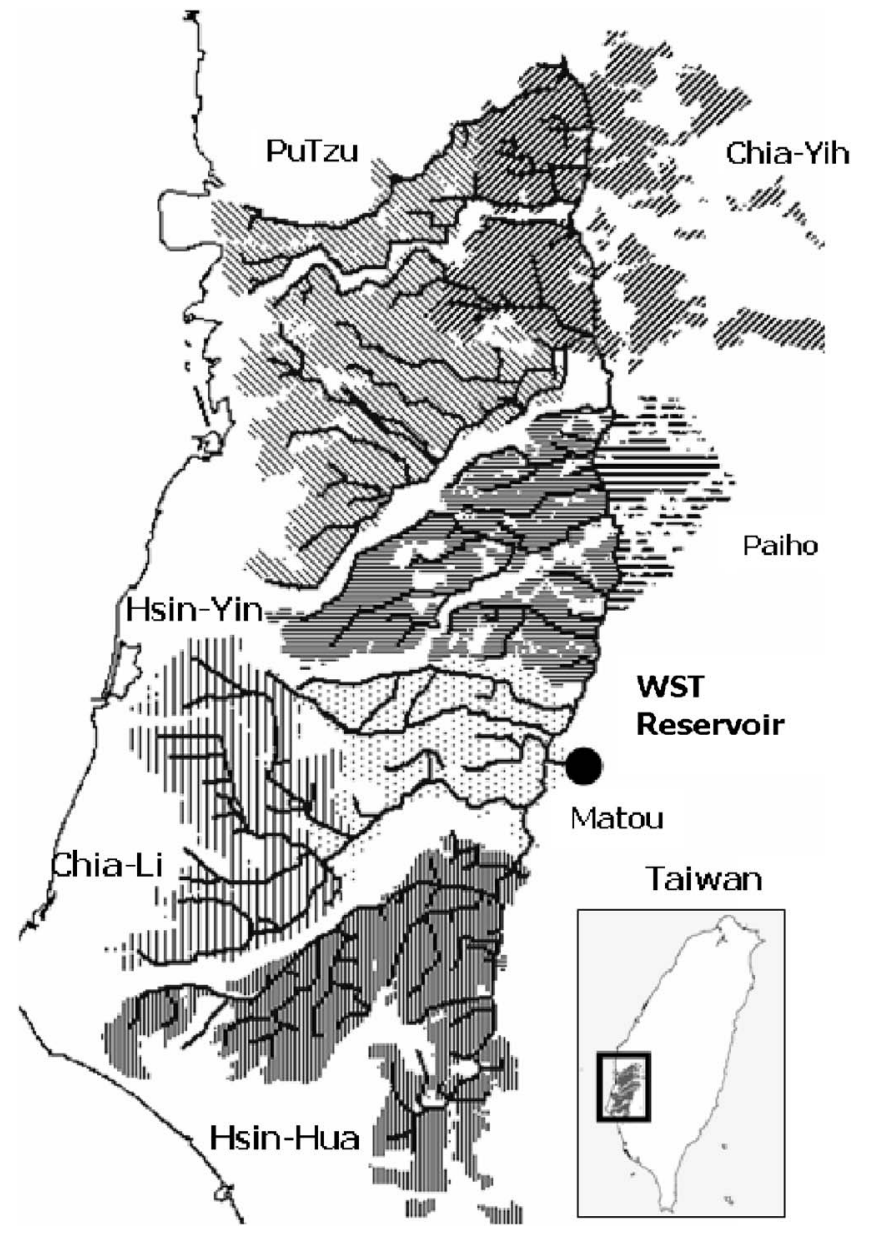

Fig. 8. Management districts of Chia-Nan Irrigation Association 

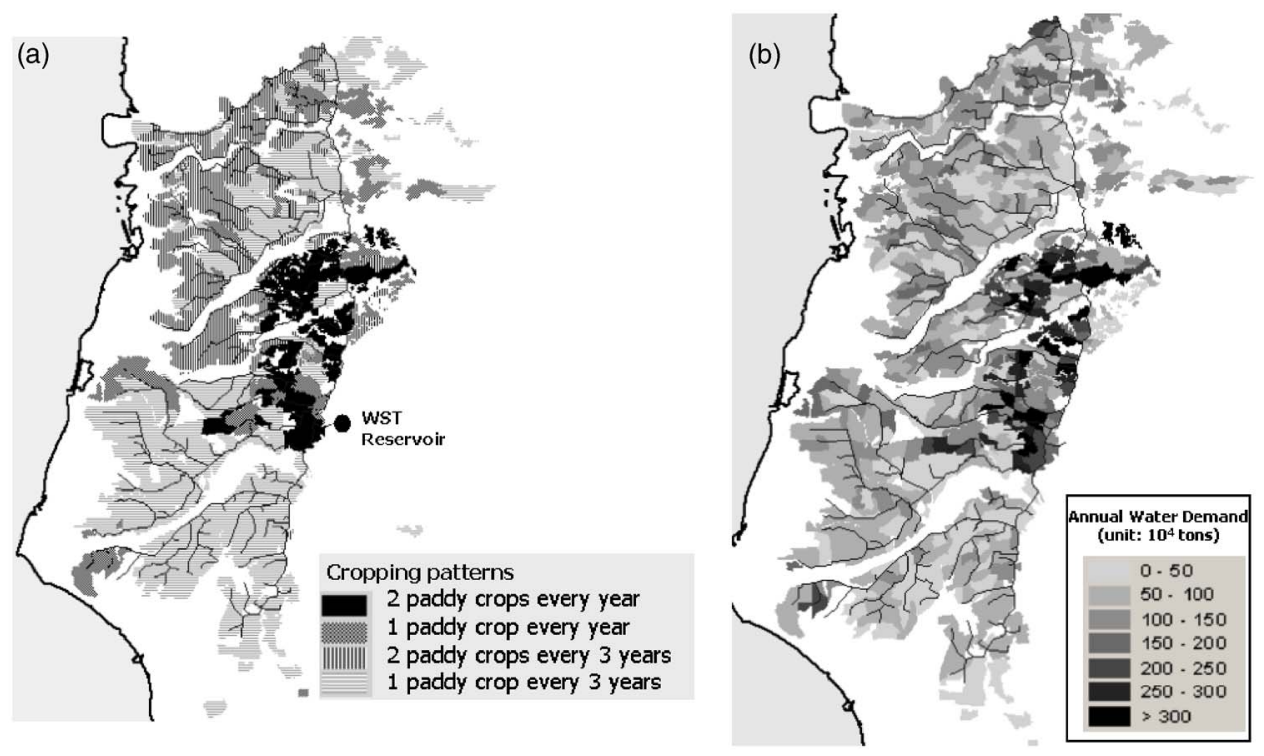

Fig. 9. (a) Cropping patterns in Chia-Nan command area; (b) spatial distribution of annual irrigation water demand in 2002

into several irrigation groups. An irrigation group of about 150 ha is used as the basic unit for practical irrigation management and spatial decisions. Although rice is the predominant cash crop in Taiwan, a rotational cropping pattern —as described in the previous section-with rice rotated with other crops such as soybean, corn, and sorghum within an irrigation group is adopted in the study area as the water supply is insufficient for an all-paddy cultivation practice.

Most areas harvesting one or two rice paddy crops per year are near the reservoir, where the water supply is adequate and steady [Fig. 9(a)]. Conversely, areas that are distant from the reservoir rotate crops as a result of insufficient water supply. Fig. 9(b) illustrates the spatial distribution of irrigation-water demand based on cropping patterns in 2002. The spatial distribution of irrigation-water demand generally coincides with the cropping patterns for that irrigated rice paddy areas [Figs. 9(a and b)].

In addition to frequent droughts, recent rapid growth in industrial and municipal water demand has pressured the agricultural sector to reduce water demand so water resources can be reallocated to other sectors, especially during droughts. The drought in 2002, the most severe in 50 years in Taiwan, is used in this case study to demonstrate how this proposed scenario-based simulation model can assist irrigation mangers in spatial decision making during drought planning and management.

Due to minimal rainfall in the first half of 2002 and the low amount of water stored in the reservoir, agricultural, municipal, and industrial sectors experienced a severe water shortage. The Chia-Nan Irrigation Association was requested to allocate 70 $\times 10^{6} \mathrm{~m}^{3}$, approximately $7.8 \%$ of the average annual irrigation water, to mitigate water shortages affecting industrial and municipal sectors. Cropping patterns were adjusted as a strategy to reduce irrigation demand in response to this severe drought. Some rice paddies were switched to other crops or left fallow to reduce water demand. The scenario-based decision process for fallow land is discussed as follows.

Water managers must determine where and how much irrigated land should be left fallow. There are two criteria used when determining which land to leave fallow: Irrigation efficiency and crop-water consumption. Based on these two criteria, three possible decision scenarios were generated and evaluated.
First, based on irrigation efficiency, water managers should consider that farms at a significant distance from water sources likely require more irrigation water due to water lost during conveyance. This is particularly true for unlined, open channel irrigation systems. When these irrigated areas are left fallow, additional water can be saved compared to that saved by leaving fields near the water source fallow. In the case study, when an area more than $35 \mathrm{~km}$ from the reservoir is left fallow, the proposed model indicates that demand is reduced by $70 \times 10^{6} \mathrm{~m}^{3}$. These fallow areas are in black in Fig. 10(A-1).

Since surface irrigation is the most common practice in Taiwan, areas with coarse soil texture can result in poor application efficiency. Leaving such farms fallow could save additional water, as water loss in such fields is typically high due to high percolation rates. The regions colored black in Fig. 10(A-2) are the areas in which the percolation rate is $>17 \mathrm{~mm} /$ day $-17 \mathrm{~mm} /$ day was adopted as the threshold after several trial simulationsconsequently, it was determined that approximately $70 \times 10^{6} \mathrm{~m}^{3}$ of water could be saved by leaving such regions fallow.

Second, rice consumes more water than other crops. As the black regions in Fig. 10(A-3) show, a large amount of water could be saved if these areas that harvest rice twice a year are left fallow. This decision could also save roughly $70 \times 10^{6} \mathrm{~m}^{3}$ of water.

According to scenario-based planning, no sequential relationships exist in planning scenario setup, and the planning framework should be the combination of different scenarios. Fig. 11 shows these three decision scenarios based on the different decision criteria. The fallow areas are in black in Fig. 11. In addition to decision scenarios based on different criteria, the optimistic, pessimistic, and most likely meteorological conditions for irrigation are also generated. Based on simulations under different conditions of climate uncertainty, decision makers can identify possible ranges of water demand. The following findings are based on results from the case study.

\section{Incorporating Climatic Uncertainty into Water-Demand Planning}

Due to the stochastic characteristics of meteorological conditions, reductions to regional irrigation water demand vary from 

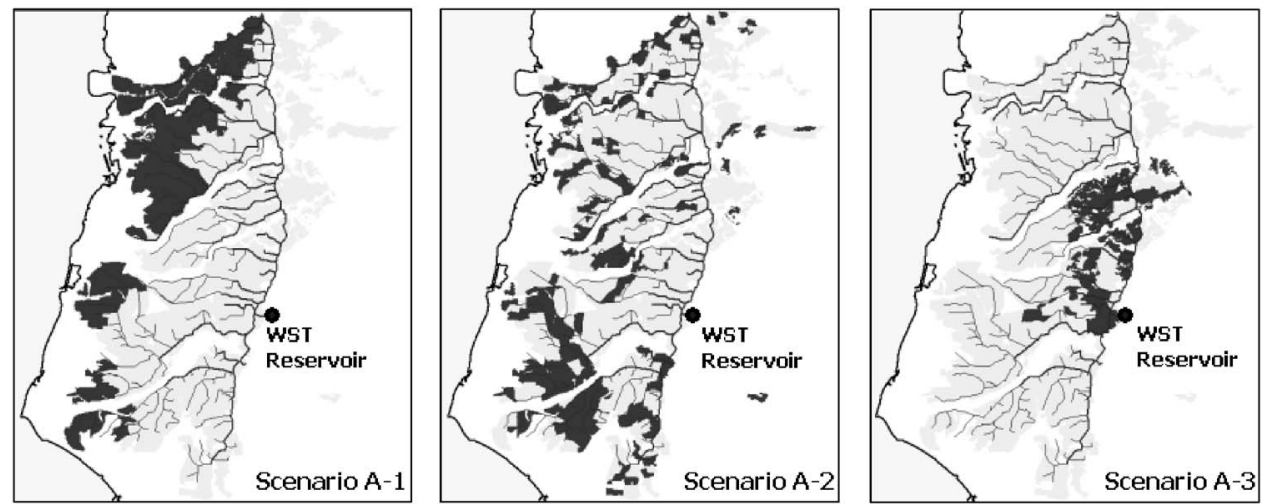

Fig. 10. Different decision scenarios for fallow strategies: Scenario A-1 is to leave area with distance from water sources longer than 35 km as fallow. Scenario A-2 is to leave area with percolation rate larger than $17 \mathrm{~mm} /$ day as fallow. Scenario A-3 is to leave area planned as two paddy crops every year as fallow. (Areas in black are fallow).

70.58 to $74.91 \times 10^{6} \mathrm{~m}^{3}$ under the three decision scenarios (Table $3)$. The range of probabilistic variation is $<3 \%$ of the total regional irrigation water demand.

\section{Relationships between Water-Demand Reduction and Fallow Areas}

The total fallow area is 21,132 ha in Scenario A-1, and $72.76-74.91 \times 10^{6} \mathrm{~m}^{3}$ of water are saved (Tables 3 and 4). Conversely, in Scenario A-3, 12,330 ha are left fallow, accounting for roughly half of the area left fallow in Scenario A-1; however, the same amount of water is saved. Efficiency of demand reduction for Scenario A-3 is highest. Notably, the amount of land left fallow is not proportional to the amount of water saved. The main reason is the percentage of fallow land that was originally planned for rice paddies. The paddy area is approximately $60 \%$ of total fallow area in Scenario A-1 and $100 \%$ of that in Scenario A-3 (Table 4). Additionally, leaving additional areas planted with paddy crops fallow could result in increased efficiency in waterdemand reduction.

\section{Comparisons of Various Performance Indices for the Impact of Fallow Areas}

As no standard decision criteria exist for choosing an optimal scenario for fallow policy, this study provided three evaluation indices for comparing fallow impacts under different criteria
(Table 5). For the scale of fallow land, the irrigated areas in Scenario A-1 were impacted most. However, from another perspective, in paddy areas in which the main cash crop in Taiwan is planted, scenario A-3 had the largest impacts.

For an overall comparison of the spatial inequity index, Scenario A-3 is most likely to cause conflicts among local farmers and local irrigation managers (Table 5). However, water managers further compared the percentage of affected regions among management districts under different scenarios. Scenario A-1 affects four management districts; however, all seven management districts are affected in Scenario A-2 (Fig. 11 and Table 6). That is, Scenario A-1 is the most probable to result in conflicts among districts due to the unequal distribution of fallow areas.

Conversely, the percentage of fallow areas originally planned for the harvest of two rice crops in the management districts should be considered as evaluation criteria for equity. The range of percentage of fallow areas in scenario A-1 is the largest (Table 7). However, from another perspective, the range of paddy percentage of fallow area among management districts is largest in Scenario A-2 (Table 8), meaning that Scenario A-2 will likely cause conflicts among managers of affected districts when fallow paddies are discussed.

\section{Discussion}

There are multiple decision rules, and in some cases conflicts among the decision criteria for choosing which land should be left
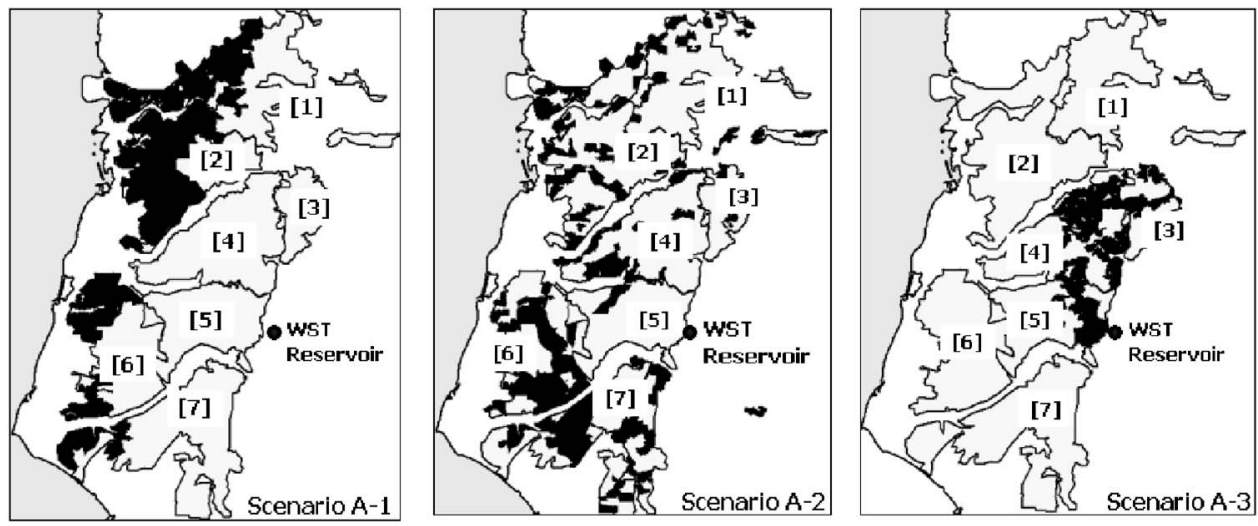

Fig. 11. Spatial distributions of fallow areas among management districts (areas in black are fallow) 
Table 3. Water-Demand Reduction under Different Decision Scenarios

\begin{tabular}{lcccc}
\hline & \multicolumn{3}{c}{ Irrigation water-demand reduction } \\
\cline { 2 - 5 } Scenarios & Optimistic & Most likely & Pessimistic & Range \\
\hline A-1 & 72.76 & 73.21 & 74.91 & 2.15 \\
A-2 & 71.11 & 72.67 & 73.12 & 2.01 \\
A-3 & 70.58 & 71.06 & 71.62 & 1.04 \\
\hline
\end{tabular}

Note: Unit: $10^{6} \mathrm{~m}^{3}$.

Table 4. Fallow Areas under Different Decision Scenarios

\begin{tabular}{lcccc}
\hline & & \multicolumn{3}{c}{ Fallow area } \\
\cline { 3 - 5 } Scenarios & Total area & Total & Paddy crop & Others \\
\hline A-1 & 73,666 & 21,132 & $12,703(60 \%)$ & $8,429(40 \%)$ \\
A-2 & 73,666 & 20,289 & $10,248(51 \%)$ & $10,041(49 \%)$ \\
A-3 & 73,666 & 12,330 & $12,330(100 \%)$ & $0(0 \%)$ \\
\hline
\end{tabular}

Note: Unit: $10^{4} \mathrm{~m}^{2}$.

Table 5. Overall Indices for the Evaluation of Fallow Areas under Different Decision Scenarios

\begin{tabular}{lcccc}
\hline & \multicolumn{2}{c}{ Fallow scale } & & Spatial equity \\
\cline { 2 - 3 } Scenarios & Irrigated areas & Paddy-farming areas & & Clustering tendency \\
\hline A-1 & 0.29 & 0.42 & 0.72 \\
A-2 & 0.28 & 0.25 & 0.58 \\
A-3 & 0.16 & 0.69 & 0.81 \\
\hline
\end{tabular}

Note: (1) The range of these indices are all from 0 to 1; and (2) the larger value indicates suffering from more serious impacts caused by fallow decision. fallow. The case study was presented that demonstrates the capability of using the proposed scenario-based framework during drought relief planning. It could also provide additional spatial insight into the decision process for negotiations among water-use sectors when competition exists for water resources during droughts. However, this study has some limitations discussed as follows.

\section{Providing Additional Performance Evaluation Indices}

This study provides water managers with spatial and temporal distributions of water demands, irrigated areas, and fallow impact indices for various scenarios. However, additional indices for evaluating the impacts of fallow policy on crop yields, food security, and agricultural stability are important to agricultural departments and farming organizations. Thus, crop-yield models, such as the decision support system for agrotechnology transfer (DSSAT), will be incorporated into the model in future studies of irrigation planning and management.

\section{Interfacing Water Demand and Supply for Further Scenario Planning}

In this study area, the Chia-Nan command area, $95 \%$ of the water is obtained from the WST Reservoir and 5\% from rivers or reused water. However, other water sources, such as groundwater, have different impacts on changes in cropping patterns. In addition to demand-side scenarios, supply-side scenarios should be consid-

Table 6. Distributions of Fallow Areas among Management Districts under Different Scenarios

\begin{tabular}{|c|c|c|c|c|}
\hline \multirow{2}{*}{$\begin{array}{l}\text { Management } \\
\text { districts }\end{array}$} & \multirow[b]{2}{*}{ Total area } & \multicolumn{3}{|c|}{ Fallow area } \\
\hline & & Scenario A-1 & Scenario A-2 & Scenario A-3 \\
\hline [1] Chia-Yih & 14,521 & $3,629(25 \%)$ & $2,255(16 \%)$ & 0 \\
\hline [2] Putzu & 17,620 & $13,073(74 \%)$ & $4,713(27 \%)$ & 0 \\
\hline [3] Paiho & 3,017 & 0 & $258(9 \%)$ & $1,660(55 \%)$ \\
\hline [4] Hsin-Yin & 11,491 & 0 & $2,606(23 \%)$ & $7,591(67 \%)$ \\
\hline [5] Matou & 7,414 & 0 & $377(5 \%)$ & $3,079(42 \%)$ \\
\hline [6] Chia-Li & 9,418 & $3,633(39 \%)$ & $5,422(58 \%)$ & 0 \\
\hline [7] Hsin-Hua & 10,185 & $797(8 \%)$ & $4,658(46 \%)$ & 0 \\
\hline Number of affected management districts & - & 4 & 7 & 3 \\
\hline Range & - & $66 \%$ & $53 \%$ & $25 \%$ \\
\hline Average & - & $37 \%$ & $26 \%$ & $55 \%$ \\
\hline
\end{tabular}

Note: Unit of area: $10^{4} \mathrm{~m}^{2}$.

Table 7. Distributions of Fallow Areas Originally Planned as Two Paddy Crops among Management Districts under Different Scenarios

\begin{tabular}{|c|c|c|c|c|}
\hline \multirow[b]{2}{*}{ Management districts } & \multirow[b]{2}{*}{ Current } & \multicolumn{3}{|c|}{ Fallow area } \\
\hline & & Scenario A-1 & Scenario A-2 & Scenario A-3 \\
\hline [1] Chia-Yih & 8,165 & $2,273(28 \%)$ & $1,428(17 \%)$ & 0 \\
\hline [2] Putzu & 10,183 & $8,050(79 \%)$ & $3,050(30 \%)$ & 0 \\
\hline [3] Paiho & 2,711 & 0 & $219(8 \%)$ & $1,660(61 \%)$ \\
\hline [4] Hsin-Yin & 9,075 & 0 & $1,690(19 \%)$ & $7,591(84 \%)$ \\
\hline [5] Matou & 5,028 & 0 & $125(3 \%)$ & $3,079(61 \%)$ \\
\hline [6] Chia-Li & 3,832 & $1,831(47 \%)$ & $1,967(51 \%)$ & 0 \\
\hline [7] Hsin-Hua & 3,693 & $549(15 \%)$ & $1,769(48 \%)$ & 0 \\
\hline Number of affected management districts & - & 4 & 7 & 3 \\
\hline Range & - & $64 \%$ & $17 \%$ & $23 \%$ \\
\hline Average & - & $42 \%$ & $25 \%$ & $69 \%$ \\
\hline
\end{tabular}

Note: Unit of area: $10^{4} \mathrm{~m}^{2}$. 
Table 8. Fallow Areas in Each Management District under Different Scenarios

\begin{tabular}{|c|c|c|c|c|c|c|c|c|c|}
\hline \multirow{2}{*}{$\begin{array}{l}\text { Management } \\
\text { districts }\end{array}$} & \multicolumn{3}{|c|}{ Scenario A-1 } & \multicolumn{3}{|c|}{ Scenario A-2 } & \multicolumn{3}{|c|}{ Scenario A-3 } \\
\hline & Total & Paddy & Others & Total & Paddy & Others & Total & Paddy & Others \\
\hline [1] Chia-Yih & 3,629 & $\begin{array}{l}2,273 \\
(63 \%)\end{array}$ & $\begin{array}{l}1,356 \\
(37 \%)\end{array}$ & 2,255 & $\begin{array}{l}1,428 \\
(63 \%)\end{array}$ & $\begin{array}{c}827 \\
(37 \%)\end{array}$ & 0 & 0 & 0 \\
\hline [2] Putzu & 13,073 & $\begin{array}{l}8,050 \\
(62 \%)\end{array}$ & $\begin{array}{l}5,023 \\
(38 \%)\end{array}$ & 4,713 & $\begin{array}{l}3,050 \\
(65 \%)\end{array}$ & $\begin{array}{l}1,663 \\
(35 \%)\end{array}$ & 0 & 0 & 0 \\
\hline [3] Paiho & 0 & 0 & 0 & 258 & $\begin{array}{c}219 \\
(85 \%)\end{array}$ & $\begin{array}{c}39 \\
(15 \%)\end{array}$ & 1,660 & $\begin{array}{c}1,660 \\
(100 \%)\end{array}$ & 0 \\
\hline [4] Hsin-Yin & 0 & 0 & 0 & 2,606 & $\begin{array}{l}1,690 \\
(65 \%)\end{array}$ & $\begin{array}{c}916 \\
(35 \%)\end{array}$ & 7,591 & $\begin{array}{c}7,591 \\
(100 \%)\end{array}$ & 0 \\
\hline [5] Matou & 0 & 0 & 0 & 377 & $\begin{array}{c}125 \\
(33 \%)\end{array}$ & $\begin{array}{c}252 \\
(67 \%)\end{array}$ & 3,079 & $\begin{array}{c}3,079 \\
(100 \%)\end{array}$ & 0 \\
\hline [6] Chia-Li & 3,633 & $\begin{array}{l}1,831 \\
(50 \%)\end{array}$ & $\begin{array}{l}1,802 \\
(50 \%)\end{array}$ & 5,422 & $\begin{array}{l}1,967 \\
(36 \%)\end{array}$ & $\begin{array}{l}3,455 \\
(64 \%)\end{array}$ & 0 & 0 & 0 \\
\hline [7] Hsin-Hua & 797 & $\begin{array}{c}549 \\
(69 \%)\end{array}$ & $\begin{array}{c}248 \\
(31 \%)\end{array}$ & 4,658 & $\begin{array}{l}1,769 \\
(38 \%)\end{array}$ & $\begin{array}{l}2,889 \\
(62 \%)\end{array}$ & 0 & 0 & 0 \\
\hline Range & - & $19 \%$ & $19 \%$ & - & $52 \%$ & $52 \%$ & - & $0 \%$ & $0 \%$ \\
\hline
\end{tabular}

Note: Unit of area: $10^{4} \mathrm{~m}^{2}$.

ered. The impacts of different water sources, operating rules, water rights, and safety yields can be constructed for further extensions. Incorporating water quality models into the proposed model is also an important issue.

\section{Portability of the Model Framework}

Although this study adopted the Chia-Nan command area for the pilot study, the general concepts in the spatial scenario-based planning framework can be transferred to other sites. Overall, decision scenarios for irrigation demand planning are also considered in irrigation practices (Table 1). However, the GIS data and related local parameters must be collected, digitized, constructed, and verified when transferring the spatial scenario-based planning framework to other sites. The standardized procedures for producing a portable framework will be documented in further study.

\section{Summary and Conclusions}

In conclusion, by incorporating water manager decision logic into scenario generation, the scenario-based planning framework provides comprehensive information and performance indices for comparing various scenarios. This study developed a novel scenario-based planning framework that generates spatial scenarios and allows water managers to compare the associated decision rules with uncertainties of stochastic phenomena and various evaluation indices, including efficiencies of saving water, and the impact of leaving land fallow. The proposed framework can be used to determine suitable cropping patterns rather than merely generating an optimal solution. Furthermore, the decision process based on scenario-based planning can satisfy water managers who realize that interactions of these factors impact specific spatial water-demand scenarios.

Moreover, spatial orientation and visualization is necessary when generating cropping pattern scenarios during irrigation planning. A GIS is incorporated into this scenario-based planning framework for capturing spatial variations in the environment. The spatial impact of each scenario can be visually analyzed. Integrating the scenario-based planning model with spatial analy- sis in the GIS generates additional understanding of spatial and temporal characteristics during irrigation planning.

\section{Acknowledgments}

This research was made possible by the funding support from the Council of Agriculture (COA) of Taiwan under Contract No. 89-AST-1.5-FOD-62(5-5). The writers would also like to acknowledge the support from the Chia-Nan Irrigation Association of Taiwan for providing field data, practical experiences, and suggestions on model implementation.

\section{References}

Allen, R. G., Pereira, L. S., Raes, D., and Smith, M. (1998). "Crop evapotranspiration." FAO Irrigation and Drainage Paper No., 56, Food and Agricultural Organization, Rome, 1-300.

Blaney, H. F., and Criddle, W. D. (1950). "Determining Water Requirement in Irrigated Areas from Climatic and Irrigation Data," Rep. No. SCS-TP, 96, USDA Soil Conservation Service, Washington, D.C.

Buras, N. (2000). "Building new water resources projects or managing existing systems?" Water Int., 25(1), 110-114.

Chang, H. H. (2006), "Risk analysis for agricultural drought," Master's thesis, National Taiwan Univ. (in Chinese with English abstract).

Deaton, M. L., and Winebrake, J. J. (1999). Dynamic modeling of environmental systems, Springer, New York.

George, B. A., Reddy, B. R. S., Raghuwanshi, N. S., and Wallender, W. W. (2002). "Decision support system for estimating reference evapotranspiration." J. Irrig. Drain. Eng., 128, 1-10.

Kipkorir, E. C., Sahli, A., and Raes, D. (2002). "MIOS: A decision tool for determination of optimal irrigated cropping pattern of a multi-crop system under water scarcity constraints." Irrig. Drain., 51, 155-166.

Klein, M. (1994). "Reengineering methodologies and tools." Inf. Sys., 11(2), 30-35.

Kumar, C. N., Indrasenan, N., and Elango, K. (1998). "Nonlinear programming model for extensive irrigation." J. Irrig. Drain. Eng., 124, $123-126$.

Kuo, S. F., Merkley, G. P., and Liu, C. W. (2000). "Decision support for irrigation project planning using a genetic algorithm." Agric. Water Manage., 45, 243-266. 
Levite, H., Sally, H., and Cour, J. (2003). "Testing water-demand management scenarios in a water-stressed basin in South Africa: Application of the WEAP model." Phys. Chem. Earth, Part B, 28(20-27), 779-786.

Lilburne, L., Watt, J., and Vincent, K. (1998). “A prototype DSS to evaluate irrigation management plans." Comput. Electron. Agric., 21, 195205.

Martin, M., Warren, R., and Stanley, G. (2003). "Rural water use, a system approach to three years of challenges with triumphs, a Queensland dairy perspective." Proc., 2003 APEN National Forum, Hobart, Australia, 26-28.

Monteith, J. L. (1965). "Evaporation and the environment. The sate and movement of water in living organisms." Proc., 19th Symp., Society of Experimental Biology, Swansea, U.K., Cambridge University Press, New York, 205-234.

Prajamwong, S., Merkley, G. P., and Allen, R. G. (1997). "Decision support model for irrigation water management." J. Irrig. Drain. Eng., 123, 106-113.

Raman, H., Mohan, S., and Rangacharya, N. C. V. (1992). "Decision support for crop planning during drought." J. Irrig. Drain. Eng., 118, 229-241.

Sabu, P., and Sudhindra, N. P. (2000). "Optimal irrigation allocation: A multilevel approach." J. Irrig. Drain. Eng., 126, 149-156.

Sattarasart, A., Sombat, S. H., and Khaobanpaew, K. (2002). "Farmers' preferences for agricultural activities under limited and uncertainty water condition in the Chao Phraya basin." Proc., Int. Symp. Sustaining Food Security and Managing Natural Resources in Southeast Asia, Thailand.

Singh, D. K., Jaiswal, C. S., Reddy, K. S., Singh, R. M., and Bhandarkar, D. M. (2001). "Optimal cropping pattern in canal command area." Agric. Water Manage., 50, 1-8.

Stewart, T. J., and Scott, L. (1995). "A scenario-based framework for multi-criteria decision analysis in water resources planning." Water Resour. Res., 31, 2835-2843.

Thornthwaite, C. W. (1948). "An approach towards a rational classification of climate." Geogr. Rev., 40, 55-94.

Wack, P. (1985). "Scenarios: Uncharted waters ahead." Harvard Bus. Rev., 85, 72-89.

Wang, S. F. (2006). "Spatial analysis for impact of fallow decision on regional irrigation demand," Master's thesis, National Taiwan Univ. (in Chinese with English abstract).

Wen, T. H., Su, M. D., and Yeh, Y. L. (2004a). “A GIS-based framework of regional irrigation water-demand assessment." Paddy and Water Environment, 2, 33-39.

Wen, T. H., Su, Y. H., and Su, M. D. (2004b). "A spatial data structure of irrigation canal systems." J. Chinese Agricultural Engineering, 50, 1-13 (in Chinese with English abstract).

Zegras, C., Sussman, J., and Conklin, C. (2004). "Scenario planning for strategic regional transportation planning." J. Urban Plann. Dev., $130,2-13$. 